\title{
Cholinium amino acid-based ionic liquids
}

\author{
Andrea Le Donne $^{1} \cdot$ Enrico Bodo $^{1}$ (D) \\ Received: 17 November 2020 / Accepted: 5 January 2021 / Published online: 14 January 2021 \\ (C) The Author(s) 2021
}

\begin{abstract}
Boosted by the simplicity of their synthesis and low toxicity, cholinium and amino acid-based ionic liquids have attracted the attention of researchers in many different fields ranging from computational chemistry to electrochemistry and medicine. Among the uncountable IL variations, these substances occupy a space on their own due to their exceptional biocompatibility that stems from being entirely made by metabolic molecular components. These substances have undergone a rather intensive research activity because of the possibility of using them as greener replacements for traditional ionic liquids. We present here a short review in the attempt to provide a compendium of the state-of-the-art scientific research about this special class of ionic liquids based on the combination of amino acid anions and cholinium cations.
\end{abstract}

Keywords Ionic liquids $\cdot$ Biocompatible ionic liquids $\cdot$ Amino acids $\cdot$ Cholinium

\section{Introduction}

Amino acid (AA)-based ionic liquids (AAILs) have emerged recently as a versatile and peculiar class of ionic liquids which have attracted attention from different fields of research owing to their biocompatibility, to the relative low cost of their synthesis, and to the availability of the reagents (Fukumoto and Ohno 2006; Ohno and Fukumoto 2007; Kirchhecker and Esposito 2016; Herrera et al. 2018; Ruivo et al. 2018). Ionic liquids (ILs) are nowadays widely known as a very varied and multifaceted set of different materials whose potential applications range from electrochemistry to medicine and from industrial processes to biomass processing agents. It is not easy to tell precisely what properties define an IL. In the recent past, ILs have been loosely defined as salts with low melting or glass transition points which display all of the following functional physico-chemical properties: solvation capabilities, ionic conductivity, low vapor pressure, and high thermal stability (Hayes et al. 2015). It is also true that, due to the sheer number of available molecular ion combinations that give rise to an IL, many of them show only a subset of these generic properties. For a more in-depth discussion of which properties actually define an ionic liquid, see the discussion by

Enrico Bodo

enrico.bodo@uniroma1.it

1 Chemistry Department, University of Rome "La Sapienza", Piazzale A. Moro 5, 00185 Rome, Italy
MacFarlane and Seddon (2007). Since their inception in the research field (Chum et al. 1975), ILs have been sometimes considered inherently "green" solvents, while recent developments have shown that their biodegradability can be low and their toxicity very high, especially for the ones which are based on fluorine compounds (Scammells et al. 2005; Petkovic et al. 2011).

Once realized that ILs are less environment-friendly than expected, part of the IL research has steered toward the quest for green and truly biocompatible ILs. One of the earliest examples of a fully biocompatible ionic compound can be traced back in 2004 (Abbott et al. 2004) where the coupling of choline chloride with organic, naturally occurring substances such as succinic and oxalic acids has been shown to produce a completely biocompatible ionic salt with melting points below $100{ }^{\circ} \mathrm{C}$. Since then, it has become clear that a cholinium cation $(\mathrm{Ch})$ might represent a competitive alternative to imidazolium both in terms of costs and in being a greener component in terms of biodegradability (Morandeira et al. 2017). At the same time, it was realized that naturally occurring organic acids could be used to replace the not environmentally benign, fluorinated anions such as $\mathrm{Tf}_{2} \mathrm{~N}$ of $\mathrm{SF}_{6}$ (Fukaya et al. 2007). Other ways to improve the green character of ILs lie in the use of renewable and available compounds for their synthesis such as naturally occurring amino acids (Hulsbosch et al. 2016). These bio-based ILs would ultimately be suitable to fully realize a green chemistry cycle starting from their synthesis and ending to their use as reaction agents (Plaquevent et al. 2008; Gomes et al. 2019). 
In cholinium-amino acid ionic liquids (ChAAILs), the deprotonated form of an amino acid is coupled to the cholinium cation. Given that, formally, the ensuing IL can be thought as emerging from the reaction of a base (choline hydroxide) and the amino acid, ChAAILs are part of the subclass of ILs known as protic ionic liquids (PILs), i.e., those substances arising from an acid base reaction or proton transfer. One of the key features of PILs is the presence of protons that spawn a hydrogen bonding network and can, at least in principle, act as efficient charge carriers. The possible chemical activity of protons in PILs has important effects not only on their nanoscopic structure (Bodo et al. 2014; Low et al. 2019) but on the bulk properties as well (Kreuer 1996); hence, it has spawned and intense research for the use of PILs as conductive materials in electrochemistry (Khan et al. 2017; Kasprzak et al. 2018; Shmukler et al. 2018; Liu and Yu 2019). It is worth noting that, among the very first attempts to obtain a fully biocompatible ILs, a different approach had also been implemented where the AA is protonated and acts as the cation (Tao et al. 2005, 2006).

In this short review, we will survey almost exclusively the class of liquids based on AA anions and the cholinium cation. In these liquids, biocompatibility stems directly (or sometimes is postulated) from the metabolic nature of the composing molecular ions. AA is the building unit of proteins and an essential component of our food. Choline (once known as vitamin B4) is a metabolite directly synthesized by the human body and is also an essential dietary nutrient. In particular, due to their reduced cost and greener properties, ILs based on cholinium have gained attention as solvent in the field of organic synthesis (Gadilohar and Shankarling 2017), and, recently, a short review focusing on their structural properties has been published (Gontrani 2018).

\section{Synthesis and physico-chemical properties}

The first synthesis of ChAAILs was reported by Ohno et al. (2007), by Moriel et al. (2010), and by Liu et al. (2012b). The most common synthetic route is based on a simple neutralization reaction between a water solution of $[\mathrm{Ch}][\mathrm{OH}]$ and the amino acid. The IL is obtained as a result of the acid-base reaction and purified by further water removal. A more controlled synthetic route employing a titration has been successively reported (De Santis et al. 2015). After it was noted that the $[\mathrm{Ch}][\mathrm{OH}]$ solution is corrosive, reactive, and more expensive than $[\mathrm{Ch}][\mathrm{Cl}]$ and that the titration procedure used by De Santis et al. (2015) is time-consuming, another synthetic variant has been recently proposed (Zhang et al. 2019; Latini et al. 2019) where they can be obtained via an ionic metathesis between potassium AA salts and $[\mathrm{Ch}][\mathrm{Cl}]$ in ethanol. A key efficiency factor in this new synthetic route is that it employs the cheap $[\mathrm{Ch}][\mathrm{Cl}]$ reagent and has a high efficiency, which makes this synthesis appealing for large-scale production or industrial applications.

An excerpt of the physical data that are available on these liquids is shown in Table 1 where we have picked a few examples for representative ChAAILs. The densities of these liquids have been found to lie within a limited range between 1.1 and $1.2 \mathrm{~g} \mathrm{~cm}^{-3}$. Densities do not simply correlate with molecular weights because the presence of multiple hydrogen bonding features is a crucial factor in determining the cohesive state of these substances.

Glass transition temperatures have been reported by Liu et al. (2012b) and lie in a wide range from -74 to $-10{ }^{\circ} \mathrm{C}$, depending on the anion structure. In contrast, De Santis et al. (2015) found [Ch][Asp] and [Ch][Glu] to become liquid only at $90{ }^{\circ} \mathrm{C}$, while they were glassy solids at $25{ }^{\circ} \mathrm{C}$. Decomposition temperatures have also been measured (Liu et al. 2012b) and turned out to be much higher than $100^{\circ} \mathrm{C}$ for all compounds, hence comparable to traditional ILs. The high decomposition temperature is an indicator of the high ionicity degree within the liquid and of how the hydrogen bonding network can be effective in stabilizing the molecular constituents.

The measurements of viscosities show significant discrepancies between the published data. In the work by Liu et al. (2012b), all viscosities were found to lie within 121$5640 \mathrm{mPa} \cdot \mathrm{s}$ at $25^{\circ} \mathrm{C}$, but much higher values were found by subsequent determinations (see Table 1, for an example). Despite differences in the actual data, it is clear that an increase in the size of the anion increases viscosity, probably because of stronger van der Waals interactions. In addition, the existence of a protic side chain (Cys, Asp, etc.) seems to be able to induce additional hydrogen bonding activity that greatly enhances viscosities. A recent study by Moosavi et al. (2019) using molecular dynamics provides calculated viscosities that are compatible with those from Liu et al. (2012b).

Conductivities are inversely related to viscosities and, despite numerical differences, have been found to loosely correlate with the anion size and its ability to spawn hydrogen bonding, two effects that tend to decrease the conductive performance.

Despite discrepancies in the measured data (that could be explained by different amounts of water contamination or by the typical metastability of some of the physical states of the compounds), a very clear picture emerges: ChAAILs are a series of homologous compounds whose molecular components feature only minor differences but present huge differences in the resulting bulk properties. Finding a simple correlation between the molecular characteristics and the bulk properties is not easy, and the latter seem to stem from a set of subtle molecular effects which are not simple to evaluate: many body effects, charge transfer phenomena, hydrogen bonding, and tautomerization reactions (see Le Donne et al. (2018) for a more in depth discussion). 
Table 1 Excerpts from published data of some physical properties of ChAAILs

\begin{tabular}{cccccccccc}
\hline AA & \multicolumn{2}{l}{ Density $\left(\mathrm{g} \mathrm{cm}^{-3}\right)$} & \multicolumn{2}{l}{ Conductivity $\left(\mu \mathrm{s} \mathrm{cm}^{-1}\right)$} & \multicolumn{2}{l}{ Viscosity $(\mathrm{mPa} \mathrm{s})$} & $T_{\mathrm{g}}\left({ }^{\circ} \mathrm{C}\right)$ & $T_{\mathrm{d}}\left({ }^{\circ} \mathrm{C}\right)$ \\
\hline Gly & $1.14^{\mathrm{a}}$ & $1.15^{\mathrm{b}}$ & $67.7^{\mathrm{a}}$ & $90.6^{\mathrm{b}}$ & $182.3^{\mathrm{a}}$ & $1230^{\mathrm{b}}$ & $121^{\mathrm{c}}$ & $-61^{\mathrm{c}}$ & $150^{\mathrm{c}}$ \\
Ala & $1.11^{\mathrm{a}}$ & $1.13^{\mathrm{b}}$ & $21.3^{\mathrm{a}}$ & $74.1^{\mathrm{b}}$ & $385.6^{\mathrm{a}}$ & $720^{\mathrm{b}}$ & $163^{\mathrm{c}}$ & $-56^{\mathrm{c}}$ & $159^{\mathrm{c}}$ \\
Pro & $1.12^{\mathrm{a}}$ & $1.14^{\mathrm{b}}$ & $0.3^{\mathrm{a}}$ & $7.5^{\mathrm{b}}$ & $10,643.8^{\mathrm{a}}$ & $9810^{\mathrm{b}}$ & $500^{\mathrm{c}}$ & $-44^{\mathrm{c}}$ & $163^{\mathrm{c}}$ \\
Ser & $1.19^{\mathrm{a}}$ & $1.20^{\mathrm{b}}$ & $9.3^{\mathrm{a}}$ & $17.5^{\mathrm{b}}$ & $11,543.7^{\mathrm{a}}$ & $12,500^{\mathrm{b}}$ & $402^{\mathrm{c}}$ & $-55^{\mathrm{c}}$ & $182^{\mathrm{c}}$ \\
\hline
\end{tabular}

${ }^{\text {a }}$ From (Tao et al. 2013)

${ }^{\mathrm{b}}$ From (De Santis et al. 2015)

${ }^{\mathrm{c}}$ From (Liu et al. 2012b)

\section{Toxicity and biodegradability}

The toxicity of ionic liquids and their activity toward living organisms are a very complex subject (Wang et al. 2007; Zhao et al. 2007; Costa et al. 2017; Kumari et al. 2020), and it would be unpractical to list here a comprehensive list of references. The nature of the interactions that drives the action of ILs on living cells has been recently summarized by Kumari et al. (2020). Many traditional ionic liquids have been revealed to be toxic for living species (Bernot et al. 2005; Docherty and Kulpa Jr. 2005; Latała et al. 2005; Peric et al. 2013). This inherent toxicity of many ILs presents a twofold issue where, from a biotechnological standpoint, the high activity of ILs toward microorganisms hinders their use as pharmaceuticals, but their toxicity opens new vistas for the implementation of ILs as antibacterial and perhaps antifungal agents (Ibsen et al. 2018; Zandu et al. 2020).

The toxicity and biodegradability of several ChAAILs have been reported since their first appearance in the field by Hou et al. (2013b), and both were found to be better than traditional ILs. A subsequent analysis by Foulet et al. (2016) showed that ChAAILs can be classified as non-toxic (or even practically harmless for [Ch][Pro]) and, as expected, that their anti-microbial activity is very low. Another study based on the antimicrobial activity of a set of several ChAAILs demonstrated that those with AA anions of high molecular weight (Glu, Arg, Phe, Try) are practically harmless to various bacterial cultures (Yazdani et al. 2016).

The advantages of using ILs in the pharmaceutical industry are associated with their use as solvents to solubilize poorly soluble drugs, thus improving delivery, and with their potential in reducing typical problems affecting solid-state drugs such as polymorphism and bioavailability (Md Moshikur et al. 2020). The use of biocompatible ILs such as ChAAILs, in this context, has obvious advantages because they allow one to circumvent the toxicity issue of other ILs. For this reason, their use as a potential drug carrier has been explored, and they were found to improve the solubility of active pharmaceutical principles (APs) and to increase their capability to penetrate the cell membranes. In particular, [Cho][Phe] and [Cho][Glu] have been tested as excipients to enhance loading and solubility of poorly soluble APs
(Caparica et al. 2018), while they did not increase the cytotoxicity of the preparations. Very recently, it was found that [Ch][Gly] and [Ch][Ala], even in small amounts, can significantly increase the solubility of ibuprofen without an increase in cytotoxicity (Yuan et al. 2020). Another recent study aimed at investigating the applicability of ChAAILs as excipients for the delivery of rutin as a potential anticancer agent (Caparica et al. 2020), and it was found that these ILs can act as safe functional excipients that are non-toxic and act to enhance the AP solubility while preserving its pharmacological activity.

\section{Interaction with complex biological molecules}

ILs consisting of biocompatible cations and anions are of great interest for biotechnology and protein chemistry because they can serve as solvents potentially able to improve protein solubility, crystallization, and stability and to ease extraction and separation (Patel et al. 2014; Wakayama et al. 2019). Out of their native environments, proteins are often unstable. During an extraction, due to the change of environment, the extracted proteins may not function properly. It therefore follows that, for practical applications, the possibility of maintaining protein integrity for a long time outside their native environment is crucial. In other words, the nature of the "storage" environment is the key to preserve proteins and their bioactivity. Unfortunately, protein-IL interactions are very complex, and, at the moment, it appears that a generalization of the observations outside particular systems is not yet possible (Benedetto 2017).

Guncheva et al. (2019) have explored the stabilization of the monomeric form of insulin in ChAAILs (Asp, Glu, Lys, Arg) and have found that, in accord with previous experiments with other ILs based on imidazolium, protein aggregation is prevented, although a partial denaturation at the expenses of $\alpha$-helices was observed.

It is generally assumed that ChAAILs act as gentle solvating agents for biomolecules. In support of this claim, a computational study (Kumari and Kashyap 2019) shows that the presence of the simplest form of ChAAIL, cholinium glycinate ([Ch][Gly]), does not disturb the structure and stability of lipid bilayers as much as traditional ILs based on imidazolium cations. Also, studies on the solvation of DNA 
(Sahoo et al. 2018) have shown only a minor binding affinity ( $\sim 4 \mathrm{kcal} / \mathrm{mol}$ ) of the ChAAIL for the macromolecule, whereby the Ch cations and not the amino acids were the main coordinating agents. Contrasting results have however been obtained by Bisht et al. (2018) where the stability of stem bromelain has been studied in the presence of both $[\mathrm{Ch}][\mathrm{Br}]$ and [Ch][Gly]: unexpectedly, [Ch][Gly] proved to be a poor stabilizer for the enzyme when compared to $[\mathrm{Ch}][\mathrm{Br}]$. More recently Kumar et al. (2020) have shown that the replacement of the tetraalkylammonium cations with cholinium in AAILs can provide a better stabilizing environment for serum albumins.

The traditional techniques for protein extraction such electrophoresis, ion exchange, and chromatography are expensive, complex, and difficult to implement on large scales. Liquid-liquid separation systems may offer a cheap substitute. For example, aqueous two-phase systems, where polymer/IL or salt/IL mixtures are dissolved in water above critical concentration, can provide a cost-effective and environmentally friendly alternative (He et al. 2012; Benedetto and Ballone 2016; Zeng et al. 2016). Since biocompatibility and low toxicity are crucial in these applications, several research efforts have been directed toward ChAAILs as alternative solvents (Song et al. 2015, 2017; Wang et al. 2016a; Zafarani-Moattar et al. 2019). Aqueous biphasic systems consisting of ChAAILs together with a water solution of polypropylene glycol seem to be a nearly optimal combination because of the ability to preserve the protein enzymatic activity and because of the general safety of the additives that could contaminate the extracted product. ChAAILs based on the use of anionic dipeptides such as [Ch][Phe-Phe] has shown superior performances in the extraction and recovery of metabolites from microalgae processing (Morandeira et al. 2020). The peculiar biocompatibility of ChAAILs has been also exploited to construct especially designed biosensors based on Gly, Ser, Phe, and His which showed good reliability, sensitivity, limit of detection, and linearity of range (Zappi et al. 2019).

With the persistent reduction of petroleum-based resources, there has been a worldwide increase in the search for alternative energy sources. In this context, biomasses represent a particularly attractive source of energy because of their availability, but their use is hampered by the difficulties and by the processing costs of extremely recalcitrant materials such as lignin and cellulose and the energy needed for it (Carlson et al. 2008). It is well-known that ILs can efficiently dissolve a large number of macromolecules otherwise difficult to solubilize (see the paper by Sun et al. (2009) and references therein) and that the extensive hydrogen bonding network that characterizes PILs could been exploited to dissolve compounds which normally require very harsh conditions and highly toxic solvents.

The ability of dissolve lignin, xylan, and cellulose was investigated for ChAAILs by Liu et al. (2012b). The lignin dissolution reached satisfactory values for most of the ChAAIL at $90{ }^{\circ} \mathrm{C}$ (the solubility is more than $140 \mathrm{mg} \mathrm{g}^{-1}$ ), but the dissolution of xylan and cellulose was much poorer with solubility values lower than $5 \mathrm{mg} \mathrm{g}^{-1}$.

Hou et al. (2013a) have reported that lignin extraction from sugar cane reached $44 \%$ using a mild condition treatment based on increasing IL concentrations of a water solution of [Ch][Lys]. Wang et al. (2016b) used a water solution of $[\mathrm{Ch}][\mathrm{Leu}]$ to extract flavonoids and pectin from ponkan peels at room temperature. In a recent paper, To et al. (2018) have shown that under very mild conditions $\left(70^{\circ} \mathrm{C}\right)$, a water solution of a set of chosen ChAAILs (Arg, Gly, Lys, and Phe) is able to extract $50 \%$ of lipids from algae biomasses. Among the AA anions, the most efficient was argininate, which yielded the best extraction performances. The structure of the argininate anion with its 6 hydrogen-bonding sites is very likely the responsible for its effectiveness.

Scarpellini et al. (2016) presented an exploratory study for paper-based cultural heritage conservation through the use of ChAAILs. They showed that a treatment with [Ch][Gly] increases the tensile strength of the fiber due to the action of the IL when the paper is subjected to artificially accelerated aging.

\section{Use as lubricants}

The first work on a tribological use of traditional ILs dates back to 2001, with a study on two different imidazolium tetrafluoroborates ILs, which showed excellent friction reduction, high load-carrying capacity, and anti-wear performance (Ye et al. 2001). The main mechanisms beyond these excellent tribological properties have to be traced in the high adhesion energies of IL onto the surfaces that induce the formation of layers between them. The possible use of ILs as lubricants focused on ILs containing halogens and specifically those made using $\left[\mathrm{BF}_{4}\right]^{-}$and $\left[\mathrm{PF}_{6}\right]^{-}$anions, but these compounds can undergo hydrolysis by moisture and generate corrosive and toxic hydrogen fluoride. The ChAAILs emerged only recently as a greener type of lubricants. The combination of two ChAAILs with lignin (Mu et al. 2015) has been investigated to evaluate the tribological properties of these mixed systems. The use of lignin as an additive improves the thermal stability and the anti-corrosive properties of the resulting mixture, thus providing excellent performance when used with commercial aluminum and iron boards.

The tribological properties of five ChAAILs have been explored using steel/steel and copper/steel contacts and turned out to be comparable to conventional IL such as $\left[\mathrm{C}_{6} \mathrm{mim}\right]\left[\mathrm{NTf}_{2}\right]$ (Jiang et al. 2018). The lubricant action has been confirmed as due to the formation of a physically adsorbed thin film of liquid on the metal surface.

In the framework on finding non-toxic lubricants, Zhang et al. (2018) have explored, in addition to the tribological 
properties, the toxicity of several ChAAILs against three aquatic organisms: brine shrimp, zebrafish, and green algae. The results show that their toxicities are significantly lower than that of traditional ILs such as 1-butyl-3-methyl imidazolium tetrafluoroborate and that ChAAILs can be used as high-performance and environmentally friendly lubricants. Hua et al. (2020) have shown that the frictional properties of [Cho][Pro] can be controlled by altering the environmental humidity. The viscosity of the ChAAIL increases at higher humidity, while it decreases when water is evaporated.

\section{ChAAIL as candidates for $\mathrm{CO}_{2}$ absorption}

The worldwide issue of $\mathrm{CO}_{2}$ emissions linked to anthropogenic global warming is one of the major concerns of this century (Stern 2007). Technologies that can offer sustainable solutions have undergone intense research, and ILs do play a role as materials which is worth investigating as a medium for $\mathrm{CO}_{2}$ absorption and storage (MacDowell et al. 2010). ILs can be incorporated into existing processing technologies, especially coal-fired power stations, to aid the separation of $\mathrm{CO}_{2}$ from flue gas (Gurkan et al. 2010a; Smiglak et al. 2014), and both theoretical and experimental studies have been performed on how ILs can interact and react with $\mathrm{CO}_{2}$ molecules. In general, the use of ILs as $\mathrm{CO}_{2}$ capture agents presents two drawbacks: limited maximum gravimetric absorption (7-9\%) and slow absorption kinetics due to the high viscosity (Bates et al. 2002), although results have been reported with a gravimetric capacity of more than $16 \%$ (Wang et al. 2010).

The challenge lies with fine-tuning IL specific reactivity and selectivity for $\mathrm{CO}_{2}$ trapping while, at the same time, providing a recyclable and biocompatible material. This is essential in order for the technology to be economically feasible and for scaling to larger and greener applications. An issue in the chemisorption of $\mathrm{CO}_{2}$ is the overall economic viability of the process because it is not a profitable industry (MacDowell et al. 2010). Even with incentives such as carbon credit schemes, it seems not plausible to eliminate the costs of carbon capture, and therefore any new IL proposed for $\mathrm{CO}_{2}$ absorption purposes must be inexpensive.

Two different $\mathrm{CO}_{2}$ absorption processes in ILs have been reported in the literature (Mumford et al. 2017; Song et al. 2019): ion structures that can react and combine with $\mathrm{CO}_{2}$ (chemisorption) or compounds that can physically dissolve $\mathrm{CO}_{2}$ (physisorption). Our interest for the present review lies in the former where $\mathrm{CO}_{2}$ is removed from flue gas using a chemical reaction that transforms it into a component of the liquid. The traditional technologies used to capture $\mathrm{CO}_{2}$ in industry settings consists of a chemical reaction of the gas with a solution of ethanolamine, which has a low cost, and a gravimetric capacity of about $7 \%$, but has major problems related to toxicity and corrosion (Rao and Rubin 2002).
A possible alternative to the ethanolamine-based approach is the use of amine-functionalized ILs which react with $\mathrm{CO}_{2}$ molecules with the formation of carbamate species and producing improved reaction stoichiometries (Camper et al. 2008; Vijayraghavan et al. 2013; Li et al. 2019). This method tends to cause large changes in solvent viscosity, yet this can be circumvented via counterions that do not promote the formation of H-bonded networks or by water addition.

Within AAILs (also those with cations different from $[\mathrm{Ch}]^{+}$), absorption can occur to various extents depending on the physical conditions and on the IL molecular composition: absorption ranges from $0.5 \mathrm{~mol}$ of $\mathrm{CO}_{2}$ per mol of IL (2:1 mechanism) up to $1 \mathrm{~mol}$ of $\mathrm{CO}_{2}$ per $1 \mathrm{~mol}$ of IL (1:1 mechanism) and sometimes higher molar fractions (1:2 mechanism). It is clear that this range of results implies the existence of different reaction mechanisms.

$\mathrm{CO}_{2}$ capture in these liquids is achieved by exploiting the $\mathrm{NH}_{2}$ group on the AA anions. The general reaction of amines with $\mathrm{CO}_{2}$ is known (Goodrich et al. 2011; Firaha and Kirchner 2016; Li et al. 2018) and can be summarized as in Scheme 1.

Whether the reaction proceeds with a 1:1 or 2:1 stoichiometry depends on what extent the second reaction takes place after the initial carbamic acid formation. In order to enhance absorption, it is necessary to favor the carbamic acid formation instead of carbamates. Gurkan et al. (2010b) explored two AAILs based on Pro and Met which have been coupled with a phosphonium cation. The absorbed molar ratio of $\mathrm{CO}_{2}$ per mol of IL was 0.9 , thus increasing by a factor of 2 the efficiency of previous setups, thanks to the possibility of favoring a carbamic acid derivative instead of the carbamate one. The gravimetric capacity, though, was still low, about 6\%.

Other authors have reported larger absorption capacity up to 1:2 M ratio. In a first work (Luo et al. 2019), a set AAILs with different basicity and steric hindrance was tested. It was found that the di-anion of a doubly deprotonated AA such as Asp showed a very high absorption capacity of $1.96 \mathrm{~mol} / \mathrm{mol}$ IL at $30^{\circ} \mathrm{C}$ and $1 \mathrm{~atm}$. Along the same route, the activation of the carboxyl group in the AA using an electron withdrawing group has also been tested increasing load factors up to $1.69 \mathrm{~mol} / \mathrm{mol}$ (Chen et al. 2016). Ammonium-based cations with longer side chains instead of cholinium have also been tested as a viable route to achieve 1:2 absorption ratios (Saravanamurugan et al. 2014). These works all incorporate AA anions in the IL, but the nature of the cationic partner can raise an environmental issue if it is toxic to the ecosystems. For this reason, ChAAILs have attracted the attention of researchers in this field because of their biodegradability and

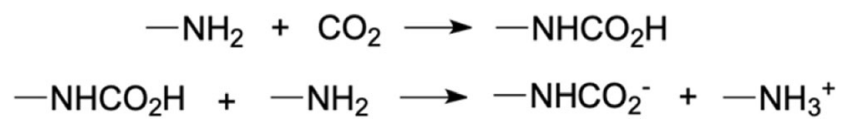

Scheme 1 General reaction for the addition of $\mathrm{CO}_{2}$ to an amino group. The first step leads to the formation of a carbamic acid derivative. The second leads to a carbamate 
inexpensive synthetic procedure due to the relative abundance of their components (Gurkan et al. 2010b; Liu et al. 2012a).

The general mechanism for addition of a single molecule of $\mathrm{CO}_{2}$ to an AA anion is reported in Scheme 2.

This reaction can be divided into two steps as shown in Scheme 2: (i) a pre-reaction complex formation (which has zwitterionic character) and (ii) a proton transfer (PT) to either carboxylate terminals. In principle the two tautomeric forms of the resulting product are in equilibrium (3), in practice, one form is often markedly more stable than the other, and the final product is only one thereby favoring either a $1: 1$ or $2: 1$ stoichiometry in the final absorption. Several approaches based on computational modeling have been used to unravel the detailed mechanism of the reaction above (Sheridan et al. 2018).

Shaikh et al. $(2016,2020)$ showed the existence of barriers associated with the proton transfer step that leads the prereaction zwitterion to the final carbamate. Mercy et al. (2016) and Onofri et al. (2020) have found that the proton transfer step in [Ch][AA] can occur via two possible reaction pathways that differ by the size of the ring that is formed in the transition state as shown in Scheme 3. The mechanism based on a 4-member ring is highly disfavored due to very high barriers, while the one with a 5-member ring has a low activation energy of only few $\mathrm{kcal} / \mathrm{mol}$.

The main problem is that the existing ChAAILs are highly viscous, limiting their applicability as agents incorporating $\mathrm{CO}_{2}$ because of its limited diffusion in the liquid. Attempts have been made to reduce the viscosity either reducing the strength of the hydrogen bonding network (Luo et al. 2016) or using ether substituents (Goodrich et al. 2011). In the latter case, the $[\mathrm{Ch}][\mathrm{Lys}]$ compound has been shown to maintain a high capture capacity of $1.62 \mathrm{~mol} / \mathrm{mol}$. The use of the doubly deprotonated forms of certain AA anions has also been explored as a tool to reduce or control the overall viscosity of the final mixture (Pan et al. 2018). Attempts at using co-solvents have been made in order to reduce the viscosities of ChAAILs. Davarpanah et al. (2020) have attempted dissolution of the IL into another solvent with high boiling point such as DMSO, but the dilution of the absorbent material led to a reduced absorption capacity (with $12.5 \mathrm{wt} \%$ IL in DMSO, only $0.3 \mathrm{~mol} \mathrm{CO}_{2} / \mathrm{mol} \mathrm{IL}$ of $\mathrm{CO}_{2}$ ).
The addition of water to ILs ( $\mathrm{Li}$ et al. 2018), in the context of $\mathrm{CO}_{2}$ absorption, is known to have beneficial effects in reducing the viscosity of the absorbent fluid. Water seems to play a two-faced role since it works by reducing viscosity and hydrogen bonding, thus increasing the diffusion of $\mathrm{CO}_{2}$, as well as removing phenomena that render the reaction site less available, but it may also act as a catalyst for the overall $\mathrm{CO}_{2}$ absorption reaction by assisting a more efficient PT. When a single water molecule was included in the transition state computational evaluation, it effectively lowered the kinetic barriers of this step (Li et al. 2018; Shaikh et al. 2020; Onofri et al. 2020) by reducing the strain on the transition state cycle as shown in Scheme 4.

Using a completely different chemical process, a set of ChAAILs has been examined by Saptal and Bhanage (2017) where 9 AA anions were used as solvent catalysts in order to help the chemical fixation of $\mathrm{CO}_{2}$ into cyclic carbonates. The binary system based on [Ch][AA]/TBAI, in particular, generated deep eutectic solvents (DESs), which were found to be highly active at atmospheric pressure with the hydroxyl functional group activating the epoxide ring and the amino group activating the $\mathrm{CO}_{2}$ molecules for reaction. In these setups, the catalyst and the co-catalyst are both recyclable up to five times without loss of catalytic activity.

\section{Structure and computational studies}

The many applications of ChAAILs have attracted the attention of computational chemists. Following the early synthesis and physical characterizations, Benedetto et al. (2014) have implemented a DFT-based study of 8 different AA anions focusing on the stability of the isolated ionic couples. Along the series of 8 AA anions, the average $[\mathrm{Ch}]^{+}[\mathrm{AA}]^{-}$interaction energy shows only minor variations and turns out to be very large, around $100 \mathrm{kcal} / \mathrm{mol}$. The anion-cation geometric binding motif in the isolated ionic couples also is rather invariant along the different AA anions and is reported in Fig. 1 for two selected examples. Apart from the obvious electrostatic interaction, the binding interaction is provided by a hydrogen bond between the cholinium hydroxyl and the AA carboxylate.
Scheme 2 General reaction mechanisms for the addition of $\mathrm{CO}_{2}$ to an $\mathrm{AA}$ anion. The first step leads to the formation of a zwitterionic adduct that evolves via proton transfer to a carbamic/ carbamate derivative which, in principle, are in equilibrium due to tautomerization reactions

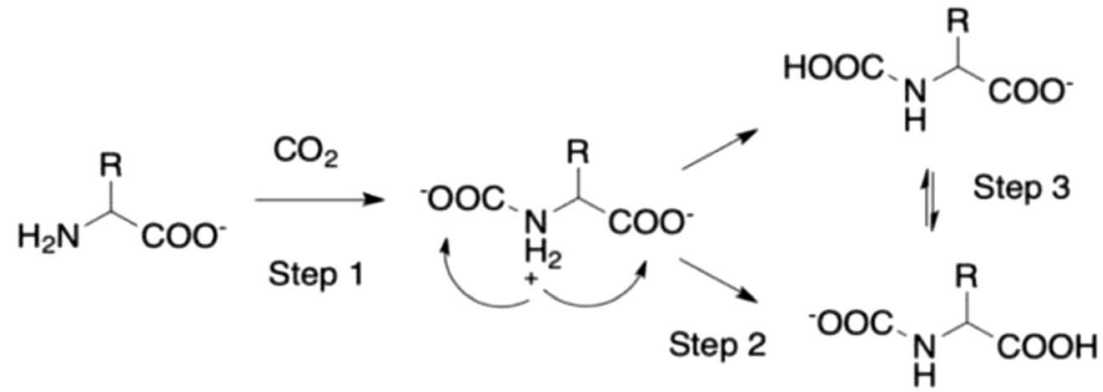


Scheme 3 Possible mechanisms of the proton transfer step with a 5 -member ring or a 4-member ring in the transition state

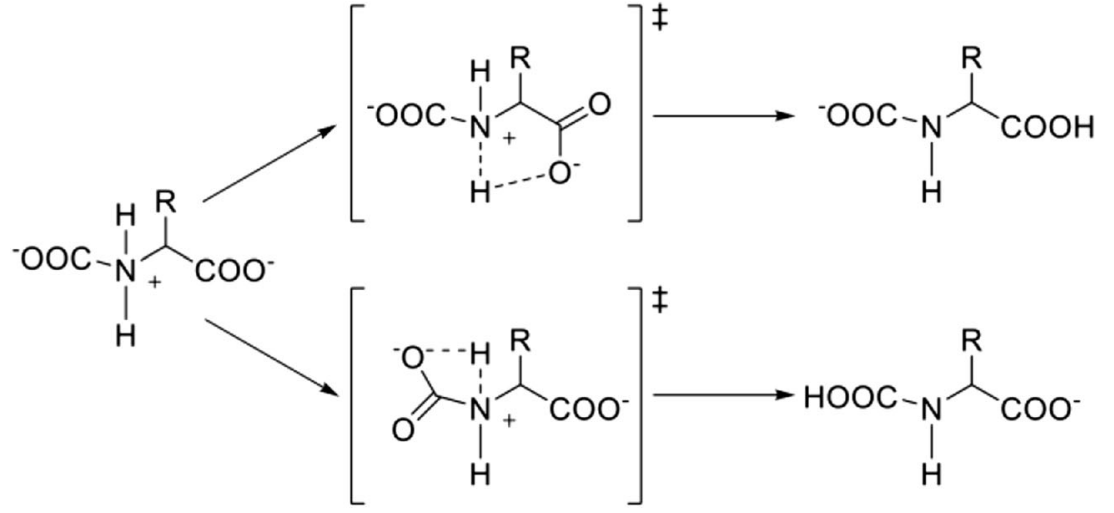

The same kind of approach was also used by del Olmo et al. (2016) extending the series of AA anions to 20 and by calculating, via the COSMO approach, bulk properties such as density and viscosity. While the data of the densities were in line with experiments, the viscosities did not match the experimental measurements, although the latter (Liu et al. 2012b; Tao et al. 2013; De Santis et al. 2015) showed noticeable differences among them. Recently, Moosavi et al. (2019) have performed molecular dynamics (MD) simulations on the ChAAILs containing [Ala], [ $\beta$-Ala], and [Phe] and computed the viscosities via the autocorrelation of the stress tensor: their data are compatible with the ones originally reported by Liu et al. (2012b), but it is well known that modeling the frictional properties of ILs using fixed charges schemes has certain accuracy limits due to the neglect of polarization and charge transfer effects.

The original conclusion that the main binding motifs in these liquids stem from the cation/anion coordination through strong hydrogen bonding has been further confirmed by using MD simulations and X-ray scattering data in a paper by Russina et al. (2016) where the subtle effects due to multiple coordination patters have also been described. The bidentate

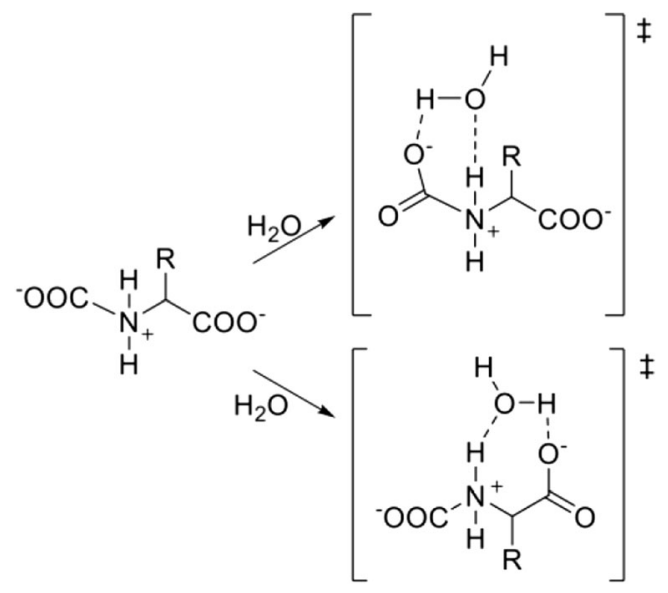

Scheme 4 Possible mechanisms of the proton transfer step with a 6member ring or a 7-member ring in the transition state when including a water molecule nature of the carboxyl unit on the AA anion can induce the existence of two kinds of coordination patterns: in the first, one anion coordinates one cation interacting with the hydroxyl and the quaternary ammonium. In the second, a single anion can coordinate simultaneously two cholinium cations by hydrogen bonds.

From the earliest computational studies, it was clear that the ChAAILs structure was not as simple as initially thought. In particular, the emergence of low-Q peaks in the X-ray diffraction patterns seemed to indicate some kind of aggregation phenomena at the nanoscale which previous calculations on isolated dimers were not able to grasp (Campetella et al. 2015b, 2016b). The authors of these studies focused on Proand Phe-based ChAAILs where the presence of structured side chains could induce and enhance the formation of transient structures at the nanoscopic level. Interestingly, ChAAILs based on Phe anions showed low-Q peaks in their $\mathrm{X}$-ray scattering pattern without having a long alkyl chain in their structure. The interpretation of the experimental diffraction data relied on the presence of correlations between second-neighbor groups (cation-cation and anion-anion) that seems to characterize the local structure in the fluids and that can induce the emergence of the spectral fingerprint of aggregation phenomena.

Analogous approaches based on a combined experimental and MD study by Gontrani et al. (2017) have elucidated, using different degrees of water dilution in the IL, the behavior of hydrogen bonding between opposite- and like-charge dimers and the intercalation structure of the final solutions. These findings agree with what was found by Shyama and Lakshmipathi (2020) where 8 [EMIM][AA] ILs were investigated by DFT calculations. Water tends to stick to anions, and only a high number of water molecules leads to the separation of the ionic dimers.

From the studies described above, it was clear that both the short- and long-range structure of these fluids was determined by a subtle balance between the weak interactions between either the molecular components with opposite charge or those with the same charge. Modeling such interactions 
Fig. 1 Example structures for the $[\mathrm{Ch}][\mathrm{Ala}]$ (left) and [Ch][Phe] (right) ionic couples. Their interaction energies as reported by Benedetto et al. (2014) are 106 and $103 \mathrm{kcal} / \mathrm{mol}$, respectively

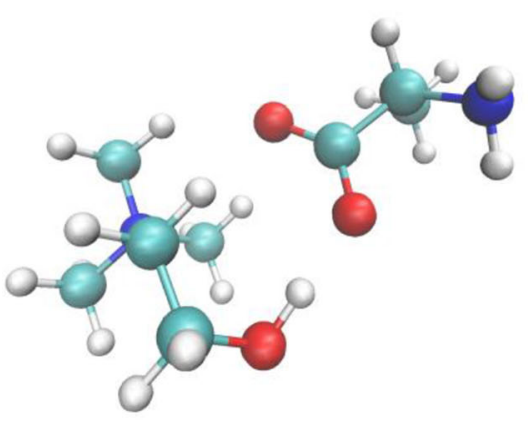

requires necessarily a great accuracy in the calculation of the interatomic potentials because of the need to describe polarization phenomena and many-body effects. In order to properly include such effects, the MD studies must be based on a first principles evaluation of the electronic energy (ab-initio MD or AIMD). In these approaches, both the size of the systems and the time scales are much reduced with respect to traditional MD techniques, but the reliability of the outcomes is generally increased. AIMD has also the advantage of accounting for anharmonic motions and providing atomic charge fluctuations so that in addition to structural information such as X-ray diffraction patterns, IR absorption spectra can be calculated as well. Known IR absorption bands of functional groups are obviously sensible to the chemical surroundings, thus providing indications on the aggregation state (Tanzi et al. 2014). The structural and spectral properties of several ChAAILs have been explored by means of AIMD, by comparing the outcomes of the simulation with both X-ray (Campetella et al. 2016a) and with IR absorption and Raman measurements (Campetella et al. 2015a, 2018). An example of the structural information available and of their accuracy with respect to experimental data is reported in Fig. 2 where the ability of AIMD to almost perfectly reproduce the structure of the fluids should be apparent. Analogous comparison of computed data with experimental IR absorption profiles can be found in the works by Campetella et al. (2015a, 2018).

As suggested by a series of works by Ludwig and coworkers (Niemann et al. 2018, 2019, 2020; Khudozhitkov et al. 2019), the interactions between like-charge ions could be a crucial ingredient in those ILs that are characterized by a high degree of H-bonding interactions. Multiple and cooperative $\mathrm{H}$-bonding features seems to be sufficient to overcome the natural Coulombic repulsion between like-charge ions, especially when the charge is delocalized over the molecular structure and the repulsion weakened by the surrounding dielectric response of the medium (polarization).

The possibility of having anionic aggregation and the extent to which like-charge interactions might contribute to the overall cohesive energy of few selected ChAAILs have been thoroughly explored in a series of papers by us and other authors. Even in the simplest AA anions with aliphatic side chains, the computational data do suggest the presence of conspicuous anion-anion pairing through $\mathrm{H}$-bonding of their amino and carboxylate groups (Fedotova et al. 2019). Le Donne et al. $(2018,2019)$ using AIMD have found a rough but evident correlation between the association energies of the dimeric anion-anion structures and the measured viscosities of the corresponding ChAAILs. A recent work by Khorrami and Kowsari (2020) based on classical MD has further extended the study of these like-charge interactions to the mixtures of ChAAILs with water.

Until recently, the possibility of having anion-anion aggregation phenomena in ChAAILs was the result of computational evidence. Very recent, though, an experimental corroboration has been obtained from the fitting of the molecular structure of $[\mathrm{Ch}][\mathrm{Phe}]$ to neutron diffraction data, thus confirming the theoretical hypothesis (Miao et al. 2020b). These experiments show that molecular segregation is present, as well as the existence of anion-rich domains which are controlled by inter-anion hydrogen bonds. These anionic aggregation phenomena might also be responsible for the low-Q correlations spotted in SAXS diffraction patterns which are otherwise difficult to attribute to more common effects such as apolar domain segregation in compounds which do not have long aliphatic chains (Miao et al. 2020a).

A pictorial example of these domains as they emerge from AIMD simulations is presented in Fig. 3 where the aggregation state of [Thr] and [Phe] anions is depicted using the atomic volumetric density in snapshots of the simulation. Examples of a trimeric $\left[\mathrm{Thr}_{3}\right]^{3-}$ and of a dimeric $\left[\mathrm{Phe}_{2}\right]^{2-}$ anionic structures are reported at the bottom.

Recent calculations by us (Campetella et al. 2017; Adenusi et al. 2020b) have shown that these anionic domains can host a rather complex chemistry due to proton transfer processes and to the respective tautomerization processes. In these works, it has been shown that $\mathrm{AA}$ anions containing an additional protic function, such as $-\mathrm{SH},-\mathrm{PO}_{3} \mathrm{H}_{2}$, or $-\mathrm{COOH}$, can exist in the form of a zwitterionic-anionic tautomer where the additional proton has moved onto the $-\mathrm{NH}_{2}$ group. The presence of multiple partial charges on the same molecular ion further weakens the overall anion-anion electrostatic repulsion and allows for even tighter anion aggregation phenomena. The 
Fig. 2 Total X-ray scattering structure factors as computed through AIMD compared to experimental measurements (no scaling involved) for [Ch][Ala], $[\mathrm{Ch}][\mathrm{Thr}],[\mathrm{Ch}][\mathrm{Phe}]$, and [Ch][Pro]. See Campetella et al. (2016a) for more details
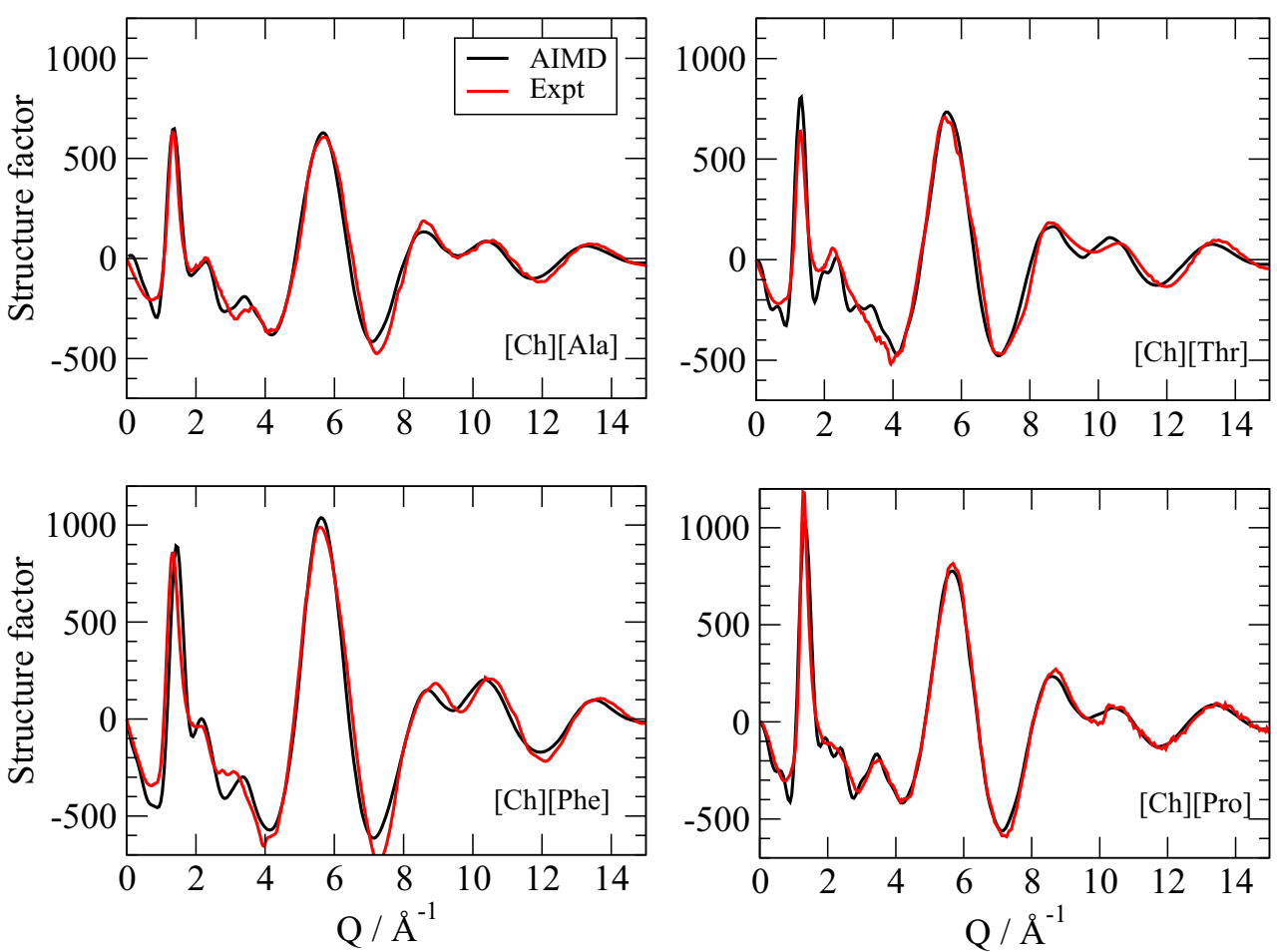
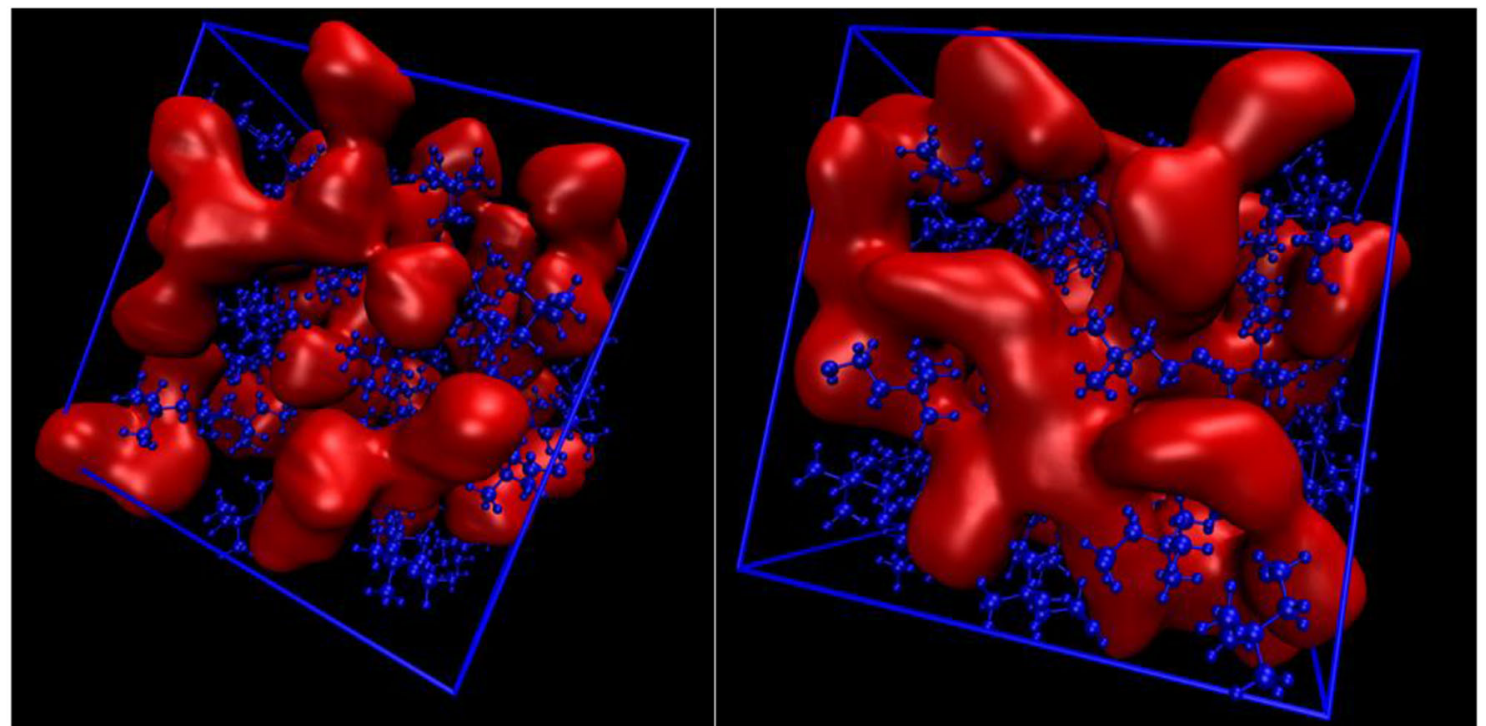
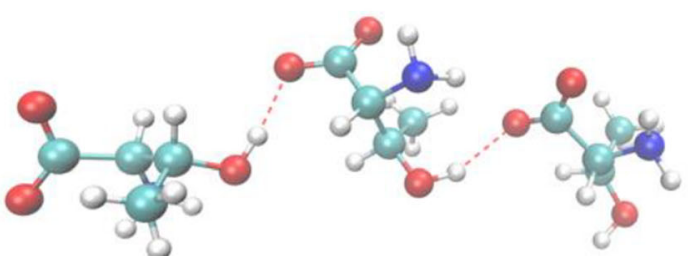

Fig. 3 Top: snapshots of AIMD simulations containing [Ch][Thr] (left) and $[\mathrm{Ch}][\mathrm{Phe}]$ (right). The anionic moieties are represented by the red isosurfaces, while the cations correspond to the blue structures. The formation of oligomers of anions is evident as well as the nano-segregation

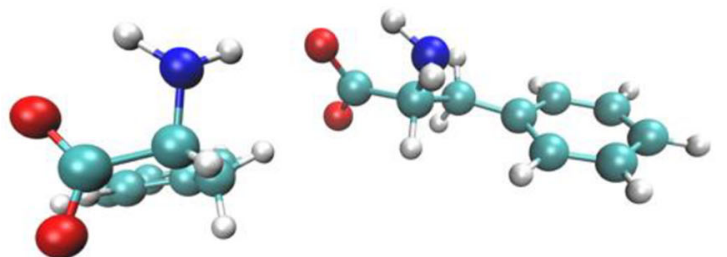

between the oppositely charged moieties. Bottom: examples of hydrogen-bonded clusters of [Thr] and [Phe] anions as extracted from the simulations at the top. For details see Le Donne et al. (2019) 


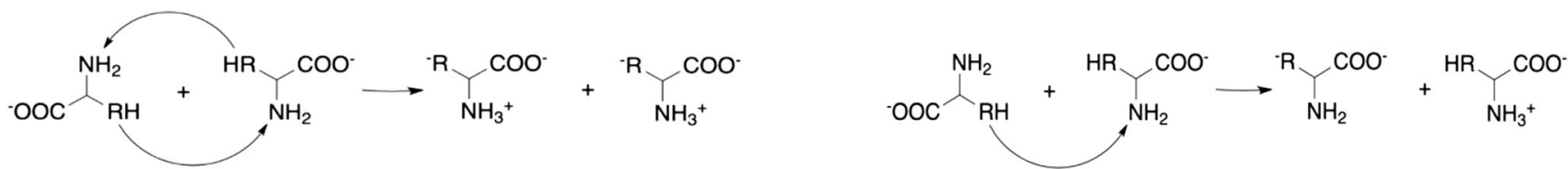

Scheme 5 Possible tautomerization reactions in AA anions with protic side chains. On the left, we report the formation of two zwitterionic anions and on the right the formation of a dianion and a neutral species. Here R represents a protic group such as $\mathrm{SH}, \mathrm{COOH}$ and $\mathrm{PO}_{3} \mathrm{H}_{2}$

mechanism of two possible tautomerization pathways in the anionic moiety of AA anions with protic side chains is reported in Scheme 5.

PILs have been, since their inception in the landscape of ionic media, an important candidate for achieving highly conductive solvents especially tailored for electrochemistry (Lu et al. 2012). The problem with these substances is that their degree of ionicity and their ability to transport charge are very dependent upon the tendency of the involved molecular species to bind the proton. The correlation between quantities such as $\mathrm{pK}_{\mathrm{a}}$ and proton affinities of the acid and base involved and the ensuing ionization degree and conductive properties of the fluid has been the subject of a great number of research activities, but it still eludes a simple generalization (Shmukler et al. 2020). The ChAAILs in which the AA anions have an additional protic function on the side chains and where the additional protons are mobile and give rise to the aforementioned tautomerization reactions might provide an exemplar ionized medium where fast charge transfer could be achieved by proton diffusion (Adenusi et al. 2020b) and point toward the development of novel conducting media (Adenusi et al. 2020a).

\section{Conclusions}

ChAAILs are a class of biocompatible ionic liquids that have attracted in recent years a vast research effort because they are emerging as suitable candidate to supplant first-generation ILs in many technological compartments. In the present review, we have summarized the results of these research efforts. These compounds have been known to be a versatile replacement for traditional ILs in various applications ranging from their use as lubricants to being efficient solvents for biomolecules, from media for protein extraction and preservation to electrochemistry. In the last part of this work, we have also summarized the results of the studies dealing with their structure at a more fundamental level which resulted in understanding that their structure is far from being trivial and shows peculiar and interesting features such as segregation phenomena that might come from the aggregation of the anionic moiety due to cooperative hydrogen bonding effects. The most recent results show that the nanoscopic structure of the anionic component can be very different from the expected, hence pointing to interesting developments for the achievement of proton conductive highly ionized media.
Funding Open Access funding provided by Università degli Studi di Roma La Sapienza.

Open Access This article is licensed under a Creative Commons Attribution 4.0 International License, which permits use, sharing, adaptation, distribution and reproduction in any medium or format, as long as you give appropriate credit to the original author(s) and the source, provide a link to the Creative Commons licence, and indicate if changes were made. The images or other third party material in this article are included in the article's Creative Commons licence, unless indicated otherwise in a credit line to the material. If material is not included in the article's Creative Commons licence and your intended use is not permitted by statutory regulation or exceeds the permitted use, you will need to obtain permission directly from the copyright holder. To view a copy of this licence, visit http://creativecommons.org/licenses/by/4.0/.

\section{References}

Abbott AP, Boothby D, Capper G, Davies DL, Rasheed RK (2004) Deep eutectic solvents formed between choline chloride and carboxylic acids: versatile alternatives to ionic liquids. J Am Chem Soc 126: 9142-9147. https://doi.org/10.1021/ja048266j

Adenusi H, Chass G, Bodo E (2020a) Theoretical insights into the structure of the aminotris(methylenephosphonic acid) (ATMP) anion: a possible partner for conducting ionic media. Symmetry 12:920. https://doi.org/10.3390/sym12060920

Adenusi H, Le Donne A, Porcelli F, Bodo E (2020b) Ab initio molecular dynamics study of phospho-amino acid-based ionic liquids: formation of zwitterionic anions in the presence of acidic side chains. J Phys Chem B 124:1955-1964. https://doi.org/10.1021/acs.jpcb. 9b09703

Bates ED, Mayton RD, Ntai I, Davis JH (2002) $\mathrm{CO}_{2}$ capture by a taskspecific ionic liquid. J Am Chem Soc 124:926-927. https://doi.org/ $10.1021 / \mathrm{ja} 017593 \mathrm{~d}$

Benedetto A (2017) Room-temperature ionic liquids meet bio-membranes: the state-of-the-art. Biophys Rev 9:309-320. https://doi. org/10.1007/s12551-017-0279-1

Benedetto A, Ballone P (2016) Room temperature ionic liquids meet biomolecules: a microscopic view of structure and dynamics. ACS Sustain Chem Eng 4:392-412. https://doi.org/10.1021/ acssuschemeng.5b01385

Benedetto A, Bodo E, Gontrani L, Ballone P, Caminiti R (2014) Amino acid anions in organic ionic compounds. An ab Initio Study of Selected Ion Pairs. J Phys Chem B 118:2471-2486. https://doi. org/10.1021/jp412281n

Bernot RJ, Kennedy EE, Lamberti GA (2005) Effects of ionic liquids on the survival, movement, and feeding behavior of the freshwater snail, Physa acuta. Environ Toxicol Chem 24:1759. https://doi.org/ 10.1897/04-614R.1

Bisht M, Jha I, Venkatesu P (2018) Does choline-based amino acid ionic liquid behave as a biocompatible solvent for stem bromelain structure? Process Biochem 74:77-85. https://doi.org/10.1016/j.procbio. 2018.07.005 
Bodo E, Mangialardo S, Capitani F, Gontrani L, Leonelli F, Postorino P (2014) Interaction of a long alkyl chain protic ionic liquid and water. J Chem Phys 140:204503. https://doi.org/10.1063/1.4876036

Camper D, Bara JE, Gin DL, Noble RD (2008) Room-temperature ionic liquid-amine solutions: tunable solvents for efficient and reversible capture of $\mathrm{CO}_{2}$. Ind Eng Chem Res 47:8496-8498. https://doi.org/ 10.1021/ie801002m

Campetella M, Bodo E, Caminiti R, Martino A, D’Apuzzo F, Lupi S, Gontrani L (2015a) Interaction and dynamics of ionic liquids based on choline and amino acid anions. J Chem Phys 142:234502. https:// doi.org/10.1063/1.4922442

Campetella M, De Santis S, Caminiti R, Ballirano P, Sadun C, Tanzi L, Gontrani L (2015b) Is a medium-range order pre-peak possible for ionic liquids without an aliphatic chain? RSC Adv 5:50938-50941. https://doi.org/10.1039/C5RA07567J

Campetella M, Bodo E, Montagna M, De Santis S, Gontrani L (2016a) Theoretical study of ionic liquids based on the cholinium cation. $A b$ initio simulations of their condensed phases. J Chem Phys 144: 104504. https://doi.org/10.1063/1.4943197

Campetella M, Martino DC, Scarpellini E, Gontrani L (2016b) Low-Q peak in X-ray patterns of choline-phenylalanine and homophenylalanine: a combined effect of chain and stacking. Chem Phys Lett 660:99-101. https://doi.org/10.1016/j.cplett.2016. 08.015

Campetella M, Montagna M, Gontrani L, Scarpellini E, Bodo E (2017) Unexpected proton mobility in the bulk phase of cholinium-based ionic liquids: new insights from theoretical calculations. Phys Chem Chem Phys 19:11869-11880. https://doi.org/10.1039/ $\mathrm{C} 7 \mathrm{CP} 01050 \mathrm{H}$

Campetella M, Le Donne A, Daniele M, Gontrani L, Lupi S, Bodo E, Leonelli F (2018) Hydrogen bonding features in cholinium-based protic ionic liquids from molecular dynamics simulations. J Phys Chem B 122:2635-2645. https://doi.org/10.1021/acs.jpcb.7b12455

Caparica R, Júlio A, Baby A, Araújo M, Fernandes A, Costa J, Santos de Almeida T (2018) Choline-amino acid ionic liquids as green functional excipients to enhance drug solubility. Pharmaceutics 10:288. https://doi.org/10.3390/pharmaceutics10040288

Caparica R, Júlio A, Araújo MEM, Baby AR, Fonte P, Costa JG, Santos de Almeida T (2020) Anticancer activity of rutin and its combination with ionic liquids on renal cells. Biomolecules 10:233. https:// doi.org/10.3390/biom10020233

Carlson TR, Vispute TP, Huber GW (2008) Green gasoline by catalytic fast pyrolysis of solid biomass derived compounds. ChemSusChem 1:397-400. https://doi.org/10.1002/cssc.200800018

Chen F-F, Huang K, Zhou Y, Tian Z-Q, Zhu X, Tao D-J, Jiang D, Dai S (2016) Multi-molar absorption of $\mathrm{CO}_{2}$ by the activation of carboxylate groups in amino acid ionic liquids. Angew Chem Int Ed 55: 7166-7170. https://doi.org/10.1002/anie.201602919

Chum HL, Koch VR, Miller LL, Osteryoung RA (1975) Electrochemical scrutiny of organometallic iron complexes and hexamethylbenzene in a room temperature molten salt. J Am Chem Soc 97:3264-3265. https://doi.org/10.1021/ja00844a081

Costa SPF, Azevedo AMO, Pinto PCAG, Saraiva MLMFS (2017) Environmental impact of ionic liquids: recent advances in (eco) toxicology and (bio)degradability. ChemSusChem 10:2321-2347. https://doi.org/10.1002/cssc.201700261

Davarpanah E, Hernández S, Latini G, Pirri CF, Bocchini S (2020) Enhanced $\mathrm{CO}_{2}$ absorption in organic solutions of biobased ionic liquids. Adv Sustain Syst 4:1900067. https://doi.org/10.1002/adsu. 201900067

De Santis S, Masci G, Casciotta F, Caminiti R, Scarpellini E, Campetella M, Gontrani L (2015) Cholinium-amino acid based ionic liquids: a new method of synthesis and physico-chemical characterization. Phys Chem Chem Phys 17:20687-20698. https://doi.org/10.1039/ C5CP01612F del Olmo L, Lage-Estebanez I, López R, García de la Vega JM (2016) Understanding the structure and properties of cholinium amino acid based ionic liquids. J Phys Chem B 120:10327-10335. https://doi. org/10.1021/acs.jpcb.6b06969

Docherty KM, Kulpa CF Jr (2005) Toxicity and antimicrobial activity of imidazolium and pyridinium ionic liquids. Green Chem 7:185. https://doi.org/10.1039/b419172b

Fedotova MV, Kruchinin SE, Chuev GN (2019) Features of local ordering of biocompatible ionic liquids: the case of choline-based amino acid ionic liquids. J Mol Liq 296:112081. https://doi.org/10.1016/j. molliq.2019.112081

Firaha DS, Kirchner B (2016) Tuning the carbon dioxide absorption in amino acid ionic liquids. ChemSusChem 9:1591-1599. https://doi. org/10.1002/cssc.201600126

Foulet A, Ghanem OB, El-Harbawi M, Lévêque J-M, Mutalib MIA, Yin C-Y (2016) Understanding the physical properties, toxicities and anti-microbial activities of choline-amino acid-based salts: lowtoxic variants of ionic liquids. J Mol Liq 221:133-138. https://doi. org/10.1016/j.molliq.2016.05.046

Fukaya Y, Iizuka Y, Sekikawa K, Ohno H (2007) Bio ionic liquids: room temperature ionic liquids composed wholly of biomaterials. Green Chem 9:1155. https://doi.org/10.1039/b706571j

Fukumoto K, Ohno H (2006) Design and synthesis of hydrophobic and chiral anions from amino acids as precursor for functional ionic liquids. ChemInform 37. https://doi.org/10.1002/chin.200647199

Gadilohar BL, Shankarling GS (2017) Choline based ionic liquids and their applications in organic transformation. J Mol Liq 227:234 261. https://doi.org/10.1016/j.molliq.2016.11.136

Gomes JM, Silva SS, Reis RL (2019) Biocompatible ionic liquids: fundamental behaviours and applications. Chem Soc Rev 48:43174335. https://doi.org/10.1039/C9CS00016J

Gontrani L (2018) Choline-amino acid ionic liquids: past and recent achievements about the structure and properties of these really "green" chemicals. Biophys Rev 10:873-880. https://doi.org/10. 1007/s12551-018-0420-9

Gontrani L, Scarpellini E, Caminiti R, Campetella M (2017) Bio ionic liquids and water mixtures: a structural study. RSC Adv 7:1933819344. https://doi.org/10.1039/C6RA28545G

Goodrich BF, de la Fuente JC, Gurkan BE, Zadigian DJ, Price EA, Huang Y, Brennecke JF (2011) Experimental measurements of aminefunctionalized anion-tethered ionic liquids with carbon dioxide. Ind Eng Chem Res 50:111-118. https://doi.org/10.1021/ie101688a

Guncheva M, Ossowicz P, Janus E, Todinova S, Yancheva D (2019) Elucidation of the effect of some cholinium amino acid ionic liquids on the thermal and the conformational stability of insulin. J Mol Liq 283:257-262. https://doi.org/10.1016/j.molliq.2019.03.074

Gurkan B, Goodrich BF, Mindrup EM et al (2010a) Molecular design of high capacity, low viscosity, chemically tunable ionic liquids for $\mathrm{CO}$ ${ }_{2}$ capture. J Phys Chem Lett 1:3494-3499. https://doi.org/10.1021/ jz101533k

Gurkan BE, de la Fuente JC, Mindrup EM, Ficke LE, Goodrich BF, Price EA, Schneider WF, Brennecke JF (2010b) Equimolar $\mathrm{CO}_{2}$ absorption by anion-functionalized ionic liquids. J Am Chem Soc 132: 2116-2117. https://doi.org/10.1021/ja909305t

Hayes R, Warr GG, Atkin R (2015) Structure and nanostructure in ionic liquids. Chem Rev 115:6357-6426. https://doi.org/10.1021/ cr500411q

He X, Huang K, Yu P, Zhang C, Xie K, Li P, Wang J, An Z, Liu H (2012) Liquid-liquid-liquid three phase extraction apparatus: operation strategy and influences on mass transfer efficiency. Chin J Chem Eng 20:27-35. https://doi.org/10.1016/S1004-9541(12)60359-0

Herrera C, Atilhan M, Aparicio S (2018) A theoretical study on mixtures of amino acid-based ionic liquids. Phys Chem Chem Phys 20: 10213-10223. https://doi.org/10.1039/C7CP08533H

Hou X-D, Li N, Zong M-H (2013a) Facile and simple pretreatment of sugar cane bagasse without size reduction using renewable ionic 
liquids-water mixtures. ACS Sustain Chem Eng 1:519-526. https:// doi.org/10.1021/sc300172v

Hou X-D, Liu Q-P, Smith TJ, Li N, Zong M-H (2013b) Evaluation of toxicity and biodegradability of cholinium amino acids ionic liquids. PLoS One 8:e59145. https://doi.org/10.1371/journal.pone.0059145

Hua J, Björling M, Larsson R, Shi Y (2020) Controllable friction of green ionic liquids via environmental humidity. Adv Eng Mater 22: 1901253. https://doi.org/10.1002/adem.201901253

Hulsbosch J, De Vos DE, Binnemans K, Ameloot R (2016) Biobased ionic liquids: solvents for a green processing industry? ACS Sustain Chem Eng 4:2917-2931. https://doi.org/10.1021/acssuschemeng. $6 \mathrm{~b} 00553$

Ibsen KN, Ma H, Banerjee A, Tanner EEL, Nangia S, Mitragotri S (2018) Mechanism of antibacterial activity of choline-based ionic liquids (CAGE). ACS Biomater Sci Eng 4:2370-2379. https://doi.org/10. 1021/acsbiomaterials.8b00486

Jiang C, Li W, Nian J, Lou W, Wang X (2018) Tribological evaluation of environmentally friendly ionic liquids derived from renewable biomaterials. Friction 6:208-218. https://doi.org/10.1007/s40544-0170170-x

Kasprzak D, Stępniak I, Galiński M (2018) Acetate- and lactate-based ionic liquids: synthesis, characterisation and electrochemical properties. J Mol Liq 264:233-241. https://doi.org/10.1016/j.molliq. 2018.05.059

Khan A, Gunawan CA, Zhao C (2017) Oxygen reduction reaction in ionic liquids: fundamentals and applications in energy and sensors. ACS Sustain Chem Eng 5:3698-3715. https://doi.org/10.1021/ acssuschemeng.7b00388

Khorrami F, Kowsari MH (2020) Tracing local nanostructure of the aqueous solutions of the biocompatible [Cho][Gly] ionic liquid: importance of hydrogen bond attraction between like-charged ions. J Phys Chem B 124:3770-3783. https://doi.org/10.1021/acs.jpcb. 0c01796

Khudozhitkov AE, Neumann J, Niemann T, Zaitsau D, Stange P, Paschek D, Stepanov AG, Kolokolov DI, Ludwig R (2019) Hydrogen bonding between ions of like charge in ionic liquids characterized by NMR deuteron quadrupole coupling constantscomparison with salt bridges and molecular systems. Angew Chem Int Ed 58:17863-17871. https://doi.org/10.1002/anie. 201912476

Kirchhecker S, Esposito D (2016) Amino acid based ionic liquids: a green and sustainable perspective. Curr Opin Green Sustain Chem 2:28 33. https://doi.org/10.1016/j.cogsc.2016.09.001

Kreuer K-D (1996) Proton conductivity: materials and applications. Chem Mater 8:610-641. https://doi.org/10.1021/cm950192a

Kumar S, Kukutla P, Devunuri N, Venkatesu P (2020) How does cholinium cation surpass tetraethylammonium cation in amino acid-based ionic liquids for thermal and structural stability of serum albumins? Int J Biol Macromol 148:615-626. https://doi.org/10. 1016/j.ijbiomac.2020.01.135

Kumari P, Kashyap HK (2019) Sensitivity and resilience of phosphatidylcholine and phosphatidylethanolamine lipid membranes against cholinium glycinate biocompatible ionic liquid. J Phys Chem B 123: 4550-4561. https://doi.org/10.1021/acs.jpcb.9b02800

Kumari P, Pillai VVS, Benedetto A (2020) Mechanisms of action of ionic liquids on living cells: the state of the art. Biophys Rev 12:11871215. https://doi.org/10.1007/s12551-020-00754-w

Latała A, Stepnowski P, Nędzi M, Mrozik W (2005) Marine toxicity assessment of imidazolium ionic liquids: acute effects on the Baltic algae Oocystis submarina and Cyclotella meneghiniana. Aquat Toxicol 73:91-98. https://doi.org/10.1016/j.aquatox.2005. 03.008

Latini G, Signorile M, Crocellà V, Bocchini S, Pirri CF, Bordiga S (2019) Unraveling the $\mathrm{CO}_{2}$ reaction mechanism in bio-based amino-acid ionic liquids by operando ATR-IR spectroscopy. Catal Today 336: 148-160. https://doi.org/10.1016/j.cattod.2018.12.050
Le Donne A, Adenusi H, Porcelli F, Bodo E (2018) Hydrogen bonding as a clustering agent in protic ionic liquids: like-charge vs oppositecharge dimer formation. ACS Omega 3:10589-10600. https://doi. org/10.1021/acsomega.8b01615

Le Donne A, Adenusi H, Porcelli F, Bodo E (2019) Structural features of cholinium based protic ionic liquids through molecular dynamics. J Phys Chem B 123:5568-5576. https://doi.org/10.1021/acs.jpcb. 9 b03314

Li W, Wen S, Shen L, Zhang Y, Sun C, Li S (2018) Mechanism and kinetic study of carbon dioxide absorption into a methyldiethanolamine/1-hydroxyethyl-3-methylimidazolium lysine/water system. Energy Fuel 32:10813-10821. https://doi.org/ 10.1021/acs.energyfuels. 8b02612

Li F, Bai Y, Zeng S, Liang X, Wang H, Huo F, Zhang X (2019) Protic ionic liquids with low viscosity for efficient and reversible capture of carbon dioxide. Int J Greenh Gas Control 90:102801. https://doi.org/ 10.1016/j.jijggc.2019.102801

Liu $\mathrm{H}, \mathrm{Yu} \mathrm{H}$ (2019) Ionic liquids for electrochemical energy storage devices applications. J Mater Sci Technol 35:674-686. https://doi. org/10.1016/j.jmst.2018.10.007

Liu A-H, Ma R, Song C et al (2012a) Equimolar $\mathrm{CO}_{2}$ capture by Nsubstituted amino acid salts and subsequent conversion. Angew Chem Int Ed 51:11306-11310. https://doi.org/10.1002/anie. 201205362

Liu Q-P, Hou X-D, Li N, Zong M-H (2012b) Ionic liquids from renewable biomaterials: synthesis, characterization and application in the pretreatment of biomass. Green Chem 14:304-307. https://doi.org/ 10.1039/C2GC16128A

Low K, Tan SYS, Izgorodina EI (2019) An ab initio study of the structure and energetics of hydrogen bonding in ionic liquids. Front Chem 7: 208. https://doi.org/10.3389/fchem.2019.00208

Lu X, Burrell G, Separovic F, Zhao C (2012) Electrochemistry of room temperature protic ionic liquids: a critical assessment for use as electrolytes in electrochemical applications. J Phys Chem B 116: 9160-9170. https://doi.org/10.1021/jp304735p

Luo XY, Fan X, Shi GL, Li HR, Wang CM (2016) Decreasing the viscosity in $\mathrm{CO}_{2}$ capture by amino-functionalized ionic liquids through the formation of intramolecular hydrogen bond. J Phys Chem B 120:2807-2813. https://doi.org/10.1021/acs.jpcb.5b10553

Luo XY, Lv XY, Shi GL, Meng Q, Li HR, Wang CM (2019) Designing amino-based ionic liquids for improved carbon capture: one amine binds two $\mathrm{CO}_{2}$. AICHE J 65:230-238. https://doi.org/10.1002/aic. 16420

MacDowell N, Florin N, Buchard A et al (2010) An overview of $\mathrm{CO}_{2}$ capture technologies. Energy Environ Sci 3:1645. https://doi.org/10. 1039/c004106h

MacFarlane DR, Seddon KR (2007) Ionic liquids - progress on the fundamental issues. Aust J Chem 60:3. https://doi.org/10.1071/ $\mathrm{CH} 06478$

Md Moshikur R, Chowdhury MDR, Moniruzzaman M, Goto M (2020) Biocompatible ionic liquids and their applications in pharmaceutics. Green Chem 10:1039.D0GC02387F. https://doi.org/10.1039/ D0GC02387F

Mercy M, de Leeuw NH, Bell RG (2016) Mechanisms of $\mathrm{CO}_{2}$ capture in ionic liquids: a computational perspective. Faraday Discuss 192: 479-492. https://doi.org/10.1039/C6FD00081A

Miao S, Atkin R, Warr GG (2020a) Amphiphilic nanostructure in choline carboxylate and amino acid ionic liquids and solutions. Phys Chem Chem Phys 22:3490-3498. https://doi.org/10.1039/C9CP06752C

Miao S, Wood J, Jiang HJ, Imberti S, Atkin R, Warr G (2020b) Unusual origin of choline phenylalaninate ionic liquid nanostructure. J Mol Liq 319:114327. https://doi.org/10.1016/j.molliq.2020.114327

Moosavi M, Banazadeh N, Torkzadeh M (2019) Structure and dynamics in amino acid choline-based ionic liquids: a combined QTAIM, NCI, DFT, and molecular dynamics study. J Phys Chem B 123: 4070-4084. https://doi.org/10.1021/acs.jpcb.9b01799 
Morandeira L, Álvarez MS, Markiewicz M, Stolte S, Rodríguez A, Sanromán MÁ, Deive FJ (2017) Testing true choline ionic liquid biocompatibility from a biotechnological standpoint. ACS Sustain Chem Eng 5:8302-8309. https://doi.org/10.1021/acssuschemeng. $7 \mathrm{~b} 02017$

Morandeira L, Sanromán MÁ, Deive FJ, Rodríguez A (2020) Cholinium dipeptide as the cornerstone to build promising separation processes: a simultaneous recovery strategy for microalgae biorefineries. Sep Purif Technol 250:117288. https://doi.org/10.1016/j.seppur.2020. 117288

Moriel P, García-Suárez EJ, Martínez M, García AB, Montes-Morán MA, Calvino-Casilda V, Bañares MA (2010) Synthesis, characterization, and catalytic activity of ionic liquids based on biosources. Tetrahedron Lett 51:4877-4881. https://doi.org/10.1016/j.tetlet. 2010.07.060

Mu L, Shi Y, Guo X, Ji T, Chen L, Yuan R, Brisbin L, Wang H, Zhu J (2015) Non-corrosive green lubricants: strengthened lignin-[choline] [amino acid] ionic liquids interaction via reciprocal hydrogen bonding. RSC Adv 5:66067-66072. https://doi.org/10. 1039/C5RA11093A

Mumford KA, Mirza NR, Stevens GW (2017) Review: room temperature ionic liquids and system designs for $\mathrm{CO}_{2}$ capture. Energy Procedia 114:2671-2674. https://doi.org/10.1016/j.egypro.2017.03.1450

Niemann T, Zaitsau D, Strate A, Villinger A, Ludwig R (2018) Cationic clustering influences the phase behaviour of ionic liquids. Sci Rep 8: 14753. https://doi.org/10.1038/s41598-018-33176-6

Niemann T, Neumann J, Stange P, Gärtner S, Youngs TGA, Paschek D, Warr GG, Atkin R, Ludwig R (2019) The double-faced nature of hydrogen bonding in hydroxy-functionalized ionic liquids shown by neutron diffraction and molecular dynamics simulations. Angew Chem Int Ed 58:12887-12892. https://doi.org/10.1002/anie. 201904712

Niemann T, Zaitsau DH, Strate A, Stange P, Ludwig R (2020) Controlling "like-likes-like" charge attraction in hydroxyfunctionalized ionic liquids by polarizability of the cations, interaction strength of the anions and varying alkyl chain length. Phys Chem Chem Phys 22:2763-2774. https://doi.org/10.1039/ C9CP06481H

Ohno H, Fukumoto K (2007) Amino acid ionic liquids. Acc Chem Res 40:1122-1129. https://doi.org/10.1021/ar700053z

Ohno H, Fukumoto K, Kagimoto J (2007) New class of ionic liquids synthesized from amino acid and other bioderived materials. In: Brennecke JF, Rogers RD, Seddon KR (eds) Ionic Liquids IV. American Chemical Society, Washington, DC, pp 351-361

Onofri S, Adenusi H, Le Donne A, Bodo E (2020) $\mathrm{CO}_{2}$ capture in ionic liquids based on amino acid anions with protic side chains: a computational assessment of kinetically efficient reaction mechanisms. ChemistryOpen 9:1153-1160. https://doi.org/10.1002/open. 202000275

Pan M, Zhao Y, Zeng X, Zou J (2018) Efficient absorption of $\mathrm{CO}_{2}$ by introduction of intramolecular hydrogen bonding in chiral amino acid ionic liquids. Energy Fuel 32:6130-6135. https://doi.org/10. 1021/acs.energyfuels.8b00879

Patel R, Kumari M, Khan AB (2014) Recent advances in the applications of ionic liquids in protein stability and activity: a review. Appl Biochem Biotechnol 172:3701-3720. https://doi.org/10.1007/ s12010-014-0813-6

Peric B, Sierra J, Martí E, Cruañas R, Garau MA, Arning J, Bottin-Weber U, Stolte S (2013) (Eco) toxicity and biodegradability of selected protic and aprotic ionic liquids. J Hazard Mater 261:99-105. https:// doi.org/10.1016/j.jhazmat.2013.06.070

Petkovic M, Seddon KR, Rebelo LPN, Silva Pereira C (2011) Ionic liquids: a pathway to environmental acceptability. Chem Soc Rev 40:1383-1403. https://doi.org/10.1039/C004968A

Plaquevent J-C, Levillain J, Guillen F, Malhiac C, Gaumont A-C (2008) Ionic liquids: new targets and media for $\alpha$-amino acid and peptide chemistry. Chem Rev 108:5035-5060. https://doi.org/10.1021/ cr068218c

Rao AB, Rubin ES (2002) A technical, economic, and environmental assessment of amine-based $\mathrm{CO}_{2}$ capture technology for power plant greenhouse gas control. Environ Sci Technol 36:4467-4475. https:// doi.org/10.1021/es0158861

Ruivo D, Canongia Lopes JN, Deive FJ, Esperança JMSS, Rebelo LPN, Rodriguez A, Shimizu K (2018) Molecular dynamics studies on the structure and interactions of ionic liquids containing amino-acid anions. Phys Chem Chem Phys 20:23864-23872. https://doi.org/ 10.1039/C8CP03831G

Russina O, De Santis S, Gontrani L (2016) Micro- and mesoscopic structural features of a bio-based choline-amino acid ionic liquid. RSC Adv 6:34737-34743. https://doi.org/10.1039/C6RA02142E

Sahoo DK, Jena S, Dutta J, Chakrabarty S, Biswal HS (2018) Critical assessment of the interaction between DNA and choline amino acid ionic liquids: evidences of multimodal binding and stability enhancement. ACS Cent Sci 4:1642-1651. https://doi.org/10.1021/ acscentsci.8b00601

Saptal VB, Bhanage BM (2017) Bifunctional ionic liquids derived from biorenewable sources as sustainable catalysts for fixation of carbon dioxide. ChemSusChem 10:1145-1151. https://doi.org/10.1002/ cssc. 201601228

Saravanamurugan S, Kunov-Kruse AJ, Fehrmann R, Riisager A (2014) Amine-functionalized amino acid-based ionic liquids as efficient and high-capacity absorbents for $\mathrm{CO}_{2}$. ChemSusChem 7:897-902 . https://doi.org/10.1002/cssc.201300691

Scammells PJ, Scott JL, Singer RD (2005) Ionic Liquids: The Neglected Issues. ChemInform:36. https://doi.org/10.1002/chin.200531232

Scarpellini E, Ortolani M, Nucara A, Baldassarre L, Missori M, Fastampa R, Caminiti R (2016) Stabilization of the tensile strength of aged cellulose paper by cholinium-amino acid ionic liquid treatment. $\mathrm{J}$ Phys Chem C 120:24088-24097. https://doi.org/10.1021/acs.jpcc. $6 \mathrm{~b} 06845$

Shaikh AR, Karkhanechi H, Kamio E, Yoshioka T, Matsuyama H (2016) Quantum mechanical and molecular dynamics simulations of dualamino-acid ionic liquids for $\mathrm{CO}_{2}$ capture. J Phys Chem C 120: 27734-27745. https://doi.org/10.1021/acs.jpcc.6b07305

Shaikh AR, Ashraf M, AlMayef T, Chawla M, Poater A, Cavallo L (2020) Amino acid ionic liquids as potential candidates for $\mathrm{CO}_{2}$ capture: combined density functional theory and molecular dynamics simulations. Chem Phys Lett 745:137239. https://doi.org/10. 1016/j.cplett.2020.137239

Sheridan QR, Schneider WF, Maginn EJ (2018) Role of molecular modeling in the development of $\mathrm{CO}_{2}$-reactive ionic liquids. Chem Rev 118:5242-5260. https://doi.org/10.1021/acs.chemrev. $8 \mathrm{~b} 00017$

Shmukler LE, Gruzdev MS, Kudryakova NO, Fadeeva YA, Kolker AM, Safonova LP (2018) Triethylammonium-based protic ionic liquids with sulfonic acids: phase behavior and electrochemistry. J Mol Liq 266:139-146. https://doi.org/10.1016/j.molliq.2018.06.059

Shmukler LE, Fedorova IV, Fadeeva YA, Safonova LP (2020) The physicochemical properties and structure of alkylammonium protic ionic liquids of RnH4-nNX ( $n=1-3)$ family. A mini-review. J Mol Liq 114350. https://doi.org/10.1016/j.molliq.2020.114350

Shyama M, Lakshmipathi S (2020) Water confined (H2O) n=1-10 amino acid-based ionic liquids - a DFT study on the bonding, energetics and IR spectra. J Mol Liq 304:112720. https://doi.org/10.1016/j. molliq.2020.112720

Smiglak M, Pringle JM, Lu X, Han L, Zhang S, Gao H, MacFarlane DR, Rogers RD (2014) Ionic liquids for energy, materials, and medicine. Chem Commun 50:9228-9250. https://doi.org/10.1039/ C4CC02021A

Song CP, Ramanan RN, Vijayaraghavan R, MacFarlane DR, Chan E-S, Ooi C-W (2015) Green, aqueous two-phase systems based on cholinium aminoate ionic liquids with tunable hydrophobicity and 
charge density. ACS Sustain Chem Eng 3:3291-3298. https://doi. org/10.1021/acssuschemeng.5b00881

Song CP, Ramanan RN, Vijayaraghavan R, MacFarlane DR, Chan E-S, Coutinho JAP, Fernandez L, Ooi C-W (2017) Primary and secondary aqueous two-phase systems composed of thermo switchable polymers and bio-derived ionic liquids. J Chem Thermodyn 115: 191-201. https://doi.org/10.1016/j.jct.2017.07.028

Song T, Avelar Bonilla GM, Morales-Collazo O, Lubben MJ, Brennecke JF (2019) Recyclability of encapsulated ionic liquids for postcombustion $\mathrm{CO}_{2}$ capture. Ind Eng Chem Res 58:4997-5007. https://doi.org/10.1021/acs.iecr.9b00251

Stern N (2007) The economics of climate change: the Stern review. Cambridge University Press, Cambridge

Sun N, Rahman M, Qin Y, Maxim ML, Rodríguez H, Rogers RD (2009) Complete dissolution and partial delignification of wood in the ionic liquid 1-ethyl-3-methylimidazolium acetate. Green Chem 11:646. https://doi.org/10.1039/b822702k

Tanzi L, Benassi P, Nardone M, Ramondo F (2014) Vibrations of bioionic liquids by ab initio molecular dynamics and vibrational spectroscopy. J Phys Chem A 118:12229-12240. https://doi.org/ 10.1021/jp5079949

Tao G, He L, Sun N, Kou Y (2005) New generation ionic liquids: cations derived from amino acids. Chem Commun:3562. https://doi.org/10. 1039/b504256a

Tao G, He L, Liu W, Xu L, Xiong W, Wang T, Kou Y (2006) Preparation, characterization and application of amino acid-based green ionic liquids. Green Chem 8:639. https://doi.org/10.1039/ b600813e

Tao D-J, Cheng Z, Chen F-F, Li Z-M, Hu N, Chen X-S (2013) Synthesis and thermophysical properties of biocompatible cholinium-based amino acid ionic liquids. J Chem Eng Data 58:1542-1548. https:// doi.org/10.1021/je301103d

To TQ, Procter K, Simmons BA, Subashchandrabose S, Atkin R (2018) Low cost ionic liquid-water mixtures for effective extraction of carbohydrate and lipid from algae. Faraday Discuss 206:93-112. https://doi.org/10.1039/C7FD00158D

Vijayraghavan R, Pas SJ, Izgorodina EI, MacFarlane DR (2013) Diamino protic ionic liquids for $\mathrm{CO}_{2}$ capture. Phys Chem Chem Phys 15: 19994. https://doi.org/10.1039/c3cp54082k

Wakayama R, Uchiyama S, Hall D (2019) Ionic liquids and protein folding - old tricks for new solvents. Biophys Rev 11:209-225. https://doi.org/10.1007/s12551-019-00509-2

Wang X, Ohlin CA, Lu Q, Fei Z, Hu J, Dyson PJ (2007) Cytotoxicity of ionic liquids and precursor compounds towards human cell line HeLa. Green Chem 9:1191. https://doi.org/10.1039/b704503d

Wang C, Luo H, Jiang D, Li H, Dai S (2010) Carbon dioxide capture by superbase-derived protic ionic liquids. Angew Chem Int Ed 49: 5978-5981. https://doi.org/10.1002/anie.201002641

Wang R, Chang Y, Tan Z, Li F (2016a) Phase behavior of aqueous biphasic systems composed of novel choline amino acid ionic liquids and salts. J Mol Liq 222:836-844. https://doi.org/10.1016/ j.molliq.2016.07.079

Wang R, Chang Y, Tan Z, Li F (2016b) Applications of choline amino acid ionic liquid in extraction and separation of flavonoids and pectin from ponkan peels. Sep Sci Technol 51:1093-1102. https://doi. org/10.1080/01496395.2016.1143006

Yazdani A, Sivapragasam M, Leveque JM, Moniruzzaman M (2016) Microbial Biocompatibility and Biodegradability of CholineAmino Acid Based Ionic Liquids. J Microb Biochem Technol:08. https://doi.org/10.4172/1948-5948.1000318

Ye C, Liu W, Chen Y, Yu L (2001) Room-temperature ionic liquids: a novel versatile lubricant. Chem Commun:2244-2245. https://doi. org $/ 10.1039 / \mathrm{b} 106935 \mathrm{~g}$

Yuan J, Wu J, Yin T (2020) Solubility and permeation enhancement of poor soluble drug by cholinium-amino acid based ionic liquids. J Drug Deliv Sci Technol 60:102037. https://doi.org/10.1016/j.jddst. 2020.102037

Zafarani-Moattar MT, Shekaari H, Jafari P (2019) Thermodynamic study of aqueous two-phase systems containing biocompatible cholinium aminoate ionic-liquids and polyethylene glycol di-methyl ether 250 and their performances for bovine serum albumin separation. $\mathrm{J}$ Chem Thermodyn 130:17-32. https://doi.org/10.1016/j.jct.2018. 10.001

Zandu SK, Chopra H, Singh I (2020) Ionic liquids for therapeutic and drug delivery applications. Curr Drug Res Rev 12:26-41. https:// doi.org/10.2174/2589977511666191125103338

Zappi D, Gabriele S, Gontrani L, Dini D, Sadun C, Marini F, Antonelli ML (2019) Biologically friendly room temperature ionic liquids and nanomaterials for the development of innovative enzymatic biosensors: part II. Talanta 194:26-31. https://doi.org/10.1016/j.talanta. 2018.10.001

Zeng C-X, Xin R-P, Qi S-J, Yang B, Wang Y-H (2016) Aqueous twophase system based on natural quaternary ammonium compounds for the extraction of proteins: other techniques. J Sep Sci 39:648654. https://doi.org/10.1002/jssc.201500660

Zhang S, Ma L, Wen P et al (2018) The ecotoxicity and tribological properties of choline amino acid ionic liquid lubricants. Tribol Int 121:435-441. https://doi.org/10.1016/j.triboint.2018.01.063

Zhang Z, Kang N, Zhou J, Li X, He L, Sui H (2019) Novel synthesis of choline-based amino acid ionic liquids and their applications for separating asphalt from carbonate rocks. Nanomaterials 9:504. https://doi.org/10.3390/nano9040504

Zhao D, Liao Y, Zhang Z (2007) Toxicity of ionic liquids. CLEAN - Soil Air Water 35:42-48. https://doi.org/10.1002/clen.200600015

Publisher's note Springer Nature remains neutral with regard to jurisdictional claims in published maps and institutional affiliations. 